\title{
Produções científicas acerca das questões étnico-raciais presente nos Cadernos
}

\author{
Escolares \\ Scientific productions about ethnic-racial issues present in School Notebooks \\ Producciones científicas sobre temas étnico-raciales presentes en Cuadernos Escolares
}

Recebido: 20/08/2021 | Revisado: 25/08/2021 | Aceito: 31/08/2021 | Publicado: 03/09/2021

\author{
Jusciléia Florêncio dos Santos \\ ORCID: https://orcid.org/0000-0002-1026-2851 \\ Universidade Federal do Amazonas, Brasil \\ E-mail: juscilea96@gmail.com \\ Maria Isabel Alonso Alves \\ ORCID: https://orcid.org/0000-0002-2960-1200 \\ Universidade Federal do Amazonas, Brasil \\ E-mail: isabelalonsojp@gmail.com
}

\begin{abstract}
Resumo
Esse artigo é um recorte de uma pesquisa em andamento no âmbito do Programa de Pós-Graduação em Ensino de Ciências e Humanidades - PPGECH da Universidade Federal do Amazonas, Brasil, Unidade Acadêmica de Humaitá/AM (UFAM/IEAA), pesquisa, na qual, o objetivo central foi analisar as questões étnico-raciais presentes nos cadernos de alunos, cujos conteúdos referem-se aos anos iniciais do ensino fundamental. Neste recorte, levantamos algumas produções científicas na Biblioteca Digital de Teses e Dissertações (BDTD) que tiveram como foco de investigação, a aplicabilidade da Lei 11.645/2008 nos conteúdos escolares dos anos iniciais do ensino fundamental e pesquisas que tiveram cadernos escolares como material empírico em suas análises e que continham a temática aqui posta como foco. As lentes teóricas utilizadas nesta abordagem estão amparadas nas perspectivas de prefixo "Pós", ou seja, Pós-Crítico, Pós-Moderno, Pós-Colonial, Estudos Culturais (EC), Estudos sobre Raça, e outros estudos que se articulam às perspectivas "pós", como o Grupo Modernidade/Colonialidade. Os resultados apontam que, com base nos trabalhos identificados, há muitas lacunas deixadas quando se trata da aplicabilidade da Lei 11.645/2008 nos conteúdos escolares registrados nos cadernos dos alunos.
\end{abstract}

Palavras-chave: Estado do conhecimento; Cadernos Escolares; Relações étnico-raciais; Lei No 11.645/2008.

\begin{abstract}
This article is an excerpt an ongoing research in the scope of the Graduate Program in Science and Humanities Teaching - PPGECH of the Federal University of Amazonas, Brazil, Academic Unit of Humaitá/AM (UFAM/IEAA), research, in which, the main objective was to analyze the ethnic-racial issues presente in the student's notebooks, whose contents refer to the early years of elementary school. In this clipping, we raise some scientific productions in the Digital Library of Theses and Dissertations (BDTD) that focused on the investigation, the applicability of Law 11,645/2008 in the school contentes of the early years of elementary school and research that had school notebooks as empirical material in their analyzes and which contained the theme put in focus here. The theoretical lenses used in this approach are supported by the perspectives of the prefix "Post", that is, Post-Critical, Post-Modern, Post-Colonial, Cultural Studies (EC), Studies on Race, and other studies that articulate with the perspectives "post" as the Modernity/Coloniality Group. The results indicate that, based on the identified works, there are many gaps letf when it comes to the applicability of Law 11,645/2008 in school contents registered in the student's notebooks.
\end{abstract}

Keyword: State of knowledge; School notebooks; Ethnic-racial relations; Law No.11.645/2008.

\section{Resumen}

Este artículo es un extracto de una investigación en curso en el ámbito del Programa de Posgrado en Docencia en Ciencias y Humanidades - PPGECH de la Universidad Federal de Amazonas, Brasil, Unidad Académica de Humaitá/AM (UFAM/IEAA), investigación, en la cual, el objetivo principal fue analizar las problemáticas étnicoraciales presentes en los cuadernos de los estudiantes, cuyos contenidos se refieren a los primeros años de la escuela primaria. En este recorte, planteamos algunas producciones científicas en la Biblioteca Digital de Tesis y Disertaciones (BDTD) que se enfocaron en la investigación, la aplicabilidad de la Ley 11.645 / 2008 en los contenidos escolares de los primeros años de la escuela primaria y las investigaciones que tenían cuadernos escolares. como material empírico en sus análisis y que contenía el tema aquí enfocado. Las lentes teóricas utilizadas en este enfoque están respaldadas por las perspectivas del prefijo "Post", es decir, Post-Critical, Post-Modern, Post-Colonial, Cultural Studies (EC), Studies on Race y otros estudios que se articulan con las perspectivas "post" como el Grupo Modernidad/Colonialidad. 
Los resultados indican que, a partir de los trabajos identificados, quedan muchas lagunas en cuanto a la aplicabilidad de la Ley 11.645 / 2008 en los contenidos escolares registrados en los cuadernos de los alumnos.

Palabras clave: Estado del conocimiento; Cuadernos escolares; Relaciones étnico-raciales; Ley N ${ }^{\circ} 11.645$ / 2008.

\section{Introdução}

O texto em tela é resultado de uma revisão bibliográfica desenvolvida no âmbito do Programa de Pós-Graduação em Ensino de Ciências e Humanidades, na Universidade Federal do Amazonas, unidade de Humaitá (PPGECH/UFAM), que teve como finalidade, mapear as produções científicas que tratam das relações étnico-raciais presentes nos conteúdos escolares dos anos iniciais, especificamente os conteúdos presentes nos cadernos dos alunos, a partir da aplicabilidade da Lei 11.645/2008. Trata-se, portanto, de um Estado do Conhecimento.

O amparo metodológico está na abordagem qualitativa e nas técnicas de pesquisa documental bibliográfica. Autoras como Ludke e André (2013) definem este tipo de pesquisa como consulta de fontes que podem ser sítios, repositórios, bibliotecas, entre outras fontes, no sentido de levantar pesquisas relacionadas ao tema investigado. Concordamos que "os documentos constituem também uma fonte poderosa de onde podem ser retiradas evidências que fundamentem afirmações e declarações do pesquisador" (Ludke \& André, 2013, p. 45). No Caso deste levantamento, optou-se pela consulta de dissertações disponibilizadas na Biblioteca Digital de Tese e Dissertações - BDTD. O tempo cronológico definido como recorte temporal a ser pesquisado compreende a criação da Lei 11.645/2008, ou seja, entre 2008 e 2020.

Em termos teóricos, para as análises dos materiais encontrados, nos apoiamos naqueles campos que se articulam ao prefixo pós (Pós-Estruturalista; Pós-Moderno; Estudos de Gênero; Estudos Culturais, Estudos Pós-Coloniais, e outros que se aproximam do mesmo viés epistemológico) e que possibilitam "perceber as diversas formas as quais os sujeitos se enredam, produzem e transitam em diversas formas de representação e identidade" (Chauma \& Alves, 2020, p. 130). Os campos teóricos mencionados embasam a ideia de que os conteúdos escolares presentes nos cadernos dos alunos estão carregados de significados - visíveis e invisíveis, sendo estes aspectos formativos capazes de produzir e/ou ressignificar identidades subjetivas no decorrer da trajetória escolar, ou seja, a escola, por meio dos conteúdos abordados e das reflexões que se faz destes, é capaz de intensificar estereótipos já presentes socialmente ou produzir significados outros que permitam o reconhecimento das diferenças, sejam estas de raça, gênero, sociais, e/ou outras. Neste sentido, os conteúdos escolares contribuem para a:

[...] produção não daquilo que nós somos, mas daquilo que nós nos tornamos [...] precisamente porque as identidades são construídas dentro e não fora do discurso [...]. Além disso, elas emergem no interior do jogo de modalidades específicas de poder e são, assim, mais o produto da marcação da diferença [...]” (Hall, 2013, p. 109).

Partindo do entendimento que as identidades são produzidas nos discursos, inclusive aqueles presentes nos currículos escolares (Silva, 1999), elas (as identidades) não podem ser vistas como algo duro, engessado, concluído, "mas uma produção inacabada, que pode ser (re)negociada sempre dentro e não fora das representações discursivas, como afirma Chauma e Alves (2020, p. 130) apoiados em Bauman (2005) e Hall (2013) quando discorrem sobre o conceito de identidade como algo que foge à fixidez e que não pode ser vista de forma inteiriça, fixa, mas sim como algo que se produz, que se ressignifica mediante discursos produzidos nos diversos contextos socioculturais, dentre os quais a escola está presente. Neste modo de pensar, cabenos refletir sobre os conteúdos escolares que abordam as questões étnico-raciais, se tais questões aparecem nos cadernos escolares e de que forma tais conteúdo são pensados/refletidos mediante as práticas de ensino em Humaitá/AM. 


\section{Metodologia}

Na busca pelo Estado do Conhecimento, consideramos as pesquisas que trazem a aplicabilidade da Lei 11.645/2008 como objeto de investigação. Para tanto, foram buscados textos divulgados em Programas de Pós-Graduação em Educação (mestrado e doutorado) no Brasil, indexadas na Biblioteca Digital de Teses e Dissertações (BDTD) a partir de 2008, recorte temporal desta pesquisa, produções cientificas/acadêmicas que tiveram como objeto de produção de dados e/ou análise, as relações étnico-raciais presente nos conteúdos escolares do iniciais do ensino básico, especialmente, produções que tiveram como fonte empírica, os cadernos dos alunos e professores, que se articulam com a temática em tela.

Para discorrer sobre o estado do conhecimento, utilizamos como apoio as discussões trazidas por Romanowski e Ens (2006), autoras que mostram procedimentos e definições acerca de mapeamentos do tipo Estado da Arte. As autoras defendem que o estado da Arte é configurado como um levantamento sobre produções científicas/acadêmicas que "desvende e examine o conhecimento já elaborado e apontem os enfoques, os temas mais pesquisados e as lacunas existentes" (Romanowski \& Ens, 2006, p. 38) sobre a temática investigada, "a fim de que se faça um balanço sobre "as produções existentes a respeito do tema pesquisado e aponte caminhos novos para a produção de pesquisas em educação, com viés, inclusive, na área do ensino" (Chauma \& Alves, 2020, p. 130).

Nesta forma de ver, o Estado da Arte possibilita ao pesquisador, uma abrangência do conhecimento produzido e disponibilizado sobre a temática investigada, podendo este ser desenvolvidos a partir dos variados de divulgação, seja por meio de material impresso, digital e outros. O Estado da arte pode contribui “com a organização e análise na definição de um campo, uma área, além de indicar possíveis contribuições da pesquisa para com as rupturas sociais” (Romanowski \& Ens, 2006, p. 38). As afirmativas postas mostram a importância e a necessidade de realizar um levantamento prévio sobre os resultados das pesquisas já desenvolvidas sobre o assunto que se pretende investigar, de modo que o pesquisador mostre os achados e analise seus resultados, assim, poderá ampliar ou criar novas perguntas sobre o assunto investigado, possibilitando novos resultados, como um movimento da pesquisa.

Sobre o movimento na pesquisa, Meyer e Paraíso (2012, p. 17) ao discorrerem sobre metodologias de pesquisas póscríticas em educação, afirmam que é preciso "construir imagens de pensamento potentes para interrogar e descrever-analisar no objeto", principalmente quando levamos em consideração que é preciso fazer novas perguntas para 'velhos' problemas, como aponta (Costa, 2007) considerando que o maior desafio dos pesquisadores é articular velhos temas em novos problemas. Concordamos que:

Pesquisar não é uma atividade que corresponde a um desejo de produzir saber, conhecimentos, e quem conhece, governa. Conhecer não é descobrir algo que existe de uma determinada forma em determinado lugar real. Conhecer é descrever, nomear, relatar, desde uma posição que é temporal, espacial e hierárquica (Costa, 2007, p. 104).

O Estado do conhecimento, neste sentido, busca ressignificar conceitos já estabelecidos, bem como apontar para novos rumos na pesquisa com os cadernos escolares sobre as questões étnico-raciais em seus conteúdos procurando identificar e analisar os aportes significativos da construção da teoria e prática pedagógica, bem como apontar possíveis estereótipos e discursos produtores de identidades presentes nos cadernos. Também é intenção mostrar possíveis restrições sobre o campo em que se move a pesquisa, as suas lacunas de disseminação, identificar experiências inovadoras investigativas que apontem problemas da prática e reconhecer as contribuições da pesquisa na constituição de propostas na área focalizada (Romanowski \& Ens, 2006, p. 39).

Assim, notamos que os objetivos postos nos estudos denominados "Estado da Arte" vão no sentido de "compreender como se dá a produção do conhecimento em uma determinada área do conhecimento em teses de doutorado, dissertações de mestrado, artigos de periódicos e publicações” (Romanowski \& Ens, 2006, p. 39). Ressaltamos, porém, que neste recorte, 
trazemos apenas o que é considerado "estado do conhecimento" por ser uma pesquisa que não abrange todos os estudos relacionados ao tema em sua totalidade, mas realizado em um recorte temporal específico (a partir de 2008).

O mapeamento, aqui considerado estado do conhecimento, foi iniciado no mês de março de 2021, em função da pesquisa de mestrado acadêmico em Ensino de Ciências e Humanidades - PPGECH/UFAM a partir deum levantamento na Biblioteca Digital de Teses e Dissertações (BDTD). Para tanto, foram buscadas produções cientificas/acadêmicas que tiveram como objeto de produção de dados e/ou análise, as relações étnico-raciais presente nos conteúdos escolares dos anos iniciais do ensino fundamental a partir de 2008 .

O processo de busca por pesquisas que abordam a temática mencionada se deu basicamente na seleção de dissertações produzidas no Brasil. Assim, o processo de busca considerou apenas os resultados que apareceram no banco do BDTD tendo como base nos descritores mencionados (Caderno de Alunos; Aplicabilidade da lei 11.645/2008; Relações Étnico-Raciais) e recorte temporal definido. Utilizando tal recurso metodológico foi possível sistematizar os dados bibliográficos de modo a mostrar as produções realizadas e refletir sobre a aplicabilidade da Lei 11645/2008 e as relações da educação étnico-raciais presentes nos cadernos escolares.

Sobre esse levantamento de dados, Morosini e Fernandes (2014, p. 108) afirmam que, "a principal característica é a natureza de uma contribuição original marcada pela identificação no novo", nesse pressuposto, entendemos ser importante as reflexões aqui postas para, assim, ampliarmos nossa visão e melhorar nosso entendimento, definir percurso e instrumentos teórico-metodológicos que ajudarão pensar e desenvolver esta pesquisa conforme o objetivo de investigação;

Nesta reflexão, faz-se necessário considerar que a construção de uma produção cientifica está relacionada não só à pessoa/pesquisador que a produz, mas a influências da instituição na qual está inserida, do país em que vive e de suas relações com a perspectiva global (Morosini \& Fernandes, 2014, p. 156).

Importante ressaltar que pesquisas cujo foco são as questões étnico-raciais podem ter ganho destaque, já que mundialmente, as mídias de comunicação têm divulgado situações de racismo nas mais variadas situações, inclusive no Brasil, país que vivencia os resquícios da colonização eurocêntrica e nega, em muitos casos, a existência do racismo e do preconceito étnico-racial, necessitando de Leis que obriguem a inserção de conteúdos escolares que deem visibilidade ao negro e negra brasileiros, bem como suas culturas e identidades. Os discursos escolares contribuem na produção identitária dos sujeitos, podendo estes reafirmarem estereótipos e racismos, ou encorajar a manifestação do respeito às diferenças. Nos apoiamos em Bhabha (2013) para pontuar o discurso como algo inerente ao processo formativo do sujeito, sendo entendido como local de cultura.

Cabe ressaltar, que é importante que o pesquisador busque conhecer sobre o que já foi publicado sobre o tema/foco escolhido para ampliar o conhecimento sobre o campo que pretende investigar, isso devido às constantes atualizações dos dados no Banco de Dados (BDTD). Conforme Romanowski e Ens (2006, p. 39), "a análise do campo investigativo é fundamental neste tempo de intensas mudanças associadas aos avanços crescentes da ciência e da tecnologia".

Assim, na busca por trabalhos que contribuísse na construção deste artigo, foram buscados no site da Capes, no qual são depositadas Teses e dissertações, resultados de pesquisas acadêmicas de várias universidades do Brasil. Os resultados estão organizados no quadro 1 a seguir, discriminando os descritores que ajudaram a buscar possíveis trabalho que pudesse ajudar a pensar está pesquisa que tem como foco perceber como vem sendo trabalhado as questões étnico-raciais conforme a Lei $\mathrm{N}^{\circ}$ 11.645/2008, para que assim, possamos pensar como desenvolver, ou quais possibilidades ou recursos foram utilizadas que contribuam em nossa proposta e no percurso que delinearemos a seguir no sentido teórico-metodológico, assim, os descritores abaixo no Quadro 1, foram parte fundamental nesta busca. 
Quadro 1: Pesquisas disponíveis na BDTD que abordam as relações étnico-raciais a partir da Lei 11.645/2008.

\begin{tabular}{|c|c|c|c|}
\hline DESCRITORES INSERIDOS & $\begin{array}{c}\text { PESQUISAS } \\
\text { ENCONTRADAS }\end{array}$ & $\begin{array}{c}\text { PESQUISAS } \\
\text { DESCARTADAS }\end{array}$ & $\begin{array}{c}\text { PESQUISAS } \\
\text { SELECIONADAS }\end{array}$ \\
\hline $\begin{array}{l}\text { Questões étnicos raciais investigações em } \\
\text { caderno }\end{array}$ & Quatro & Três & Uma \\
\hline Questões étnico racial & Duzentos noventa & $\begin{array}{l}\text { Duzentos e oitenta e } \\
\text { cinco }\end{array}$ & Cinco \\
\hline Lei $11.645 / 2008$ & Cinquenta e cinco & Cinquenta e quatro & Uma \\
\hline Aplicabilidade da Lei 11.645/08 & Onze & Onze & Nenhuma \\
\hline Aplicabilidade da lei $11.645 / 08$ nos anos iniciais & Dois & Dois & Nenhuma \\
\hline Investigação em caderno de aluno & $\begin{array}{l}\text { Duzentos e trinta e } \\
\text { cinco }\end{array}$ & Duzentos e trinta e cinco & Nenhuma \\
\hline Investigação em caderno nos anos iniciais & Sessenta e dois & Sessenta e dois & nenhuma \\
\hline Relação da educação étnico racial & Duzentos e vinte e um & Duzentos e dezoito & Três \\
\hline Ensino de História e Cultura Afro Brasileira & Quatrocentos e doze & Quatrocentos e dez & Duas \\
\hline
\end{tabular}

Fonte: Informações extraídas da CAPES/BDTD, organizadas pelas autoras.

De acordo com os descritores pesquisados, foram selecionados alguns trabalhos cujos títulos, a priori, se destacaram por se tratar de investigações sobre questões étnico-racial e aplicabilidade da 11.645/2008. Assim, a escolha, posteriormente, se deu mediante leitura prévia do resumo dos trabalhos, bem como de seus resultados. Pesquisas que se aproximavam pela temática ou pela abordagem metodológica estavam no foco do recorte temático, bem como o recorte temporal, ou seja, trabalhos de pesquisa concluídos a partir de 2008, ano de criação da Lei 11.645.

Apesar do recorte temporal já especificado, cabe ressaltar a 10.639/2003, que antecede a lei 11.645/2008, assinada pelo presidente da República Luiz Inácio Lula da Silva alterou a Lei de Diretrizes e Bases da Educação 9.394, de 20 de dezembro de 1996 com o artigo 26-A incluindo no currículo oficial da rede pública e privada de Ensino a obrigatoriedade da temática "História e Cultura Afro-Brasileira", "História e Cultura Indígena", sendo, posteriormente reforçada com a Lei 11645/2008, possibilitando novas perspectivas no Ensino Público e proporcionando aos alunos do ensino básico uma formação que promova o conhecimento e a importância da participação dos negros e indígena na história do Brasil.

\section{Um olhar sobre a condição subalterna do negro no Brasil}

Embora a prática da escravidão já existia no mundo desde as primeiras civilizações, está se perdurou por mais tempo em relação aos negros, especialmente no Brasil, por isso é importante ressaltar que a história brasileira foi construída base na mão de obra escravizada africana e indígena.

Diante desse processo de escravidão é importante ressaltar como se originou e se adjetivou a palavra negro mediante um processo de colonização classificatório, seletivo, desigual, binário e polarizado. De acordo com Nunes a palavra negro tem sua origem latim, diretamente associado aos sujeitos de cor de pele escura, que foram escravizados sendo está uma expressão usada inicialmente pelos Espanhóis para se referirem aos escravos na América, assim, "negro - Etimologicamente, este termo vem do latim Níger (da margem do rio Níger/nigeriano), e está associado ao sistema de classificação racial de seres humanos com fenótipo da pele mais escura, em relação a outros grupos raciais” (Nunes, 2017, p. 5).

De acordo com Nunes (2017), a ideia de raça é antiga e provavelmente nascida entre meados do V e VII a.C, época em que se dava as primeiras marcações de divisões do mar mediterrâneo, surgiam as discórdias coloniais na antiga Grécia, enfatizava-se a ideia de divisão de raça. Dessa forma compreendemos que as divisões, classificações de sujeitos por raça/cor e grupo étnico vem se formando ao longo de séculos de história, e se mantem até o século XXI. 
Essas ideias trazidas ao Brasil inculcaram-se de tal forma, que se perdura até 2021. Por meio de fatos divulgados pelas mídias que mostram vários tipos violências e discriminação contra o negro.

O racismo existente no contexto brasileiro tem sido produzido nos diferentes discursos, inclusive aqueles voltados para os conteúdos escolares relacionados à história afro-brasileira sob o ponto de vista colonial que lembra os negros "sem alma", destinados à subordinação eurocêntrica. Os conteúdos didáticos, quando visto a partir da decolonialidade, mostram um processo histórico marcado por barbáries provocados pela negação do outro, do sujeito negro escravizado, que classificam de forma excludente aqueles sujeitos que não se "encaixam” nos perfis eurocêntricos. Concordamos com Quijano (2005, p.37) ao afirmar que:

A colonialidade é um dos elementos constitutivos e específicos do padrão mundial do poder capitalista. Sustenta-se na imposição de uma classificação racial/étnica da população do mundo como pedra angular do referido padrão de poder e opera em cada um dos planos, meios e dimensões, materiais e subjetivos, da existência social quotidiana e da escala societal.

No Brasil, esses marcadores de classificação étnico-racial se deram por critérios fenotípicos, sendo a cor da pele a característica mais relevante para a definição nesta classificação, ou como pontua Queiroz (2004), o sujeito negro/afrodescente ocupa sua posição na escala de cor também conforme condições sociais, econômicas, e formação escolar. Sob esse olhar, concordamos com Fernandes (2017, p. 148) que:

Historicamente, a população negra escravizada foi excluída do direito a escolar por ser estrangeiros pobres e por serem negros escravizados. Esse fato fez com que seus descendentes herdassem uma cultura de famílias analfabetas, pobres, com pouca instrução e com pequenas chances de ter sucesso na trajetória escolar. Esse contexto justifica o fato de haver a necessidade de se reservar vagas para alunas e alunos que enfrentam desafios inerentes ao seu histórico familiar, econômico [...].

Por isso a urgência na efetivação da lei 11.645/08 para que haja uma mudança e compreensão da importância do negro e afrodescendente na participação da construção histórica brasileira, bem como, nas ações de reparação aos danos causados a essa parcela da população, que hoje através cotas consegue adentrar aos espaços das universidades que antes era espaço privilegiados e reservados as pessoas brancas. O esperado é que através da efetivação da Lei 11.645/2008 haja transformação no processo de formação no ensino básico, que a educação seja o portal o fio condutor nesse processo de transformações, que por séculos tem marginalizado, selecionado e excluído os sujeitos por conta da cor da sua pele.

\section{O estado do conhecimento em relação à pesquisa sobre as questões étnico-raciais presente nos cadernos escolares}

Ao pesquisar sobre a presença das questões étnico-raciais nos cadernos escolares a partir da aplicabilidade da lei 11.645/2008 nos deparamos com trabalhos considerados relevantes para a temática posta. Porém, anterior ao recorte proposto 2008-2020 - encontramos o trabalho de Faria (1988), que buscou mostrar o caderno como foco de investigação, e, por ser o caderno de aluno o objeto empírico da pesquisa mencionada, este autor tem sido referência para outras pesquisas cujo foco é o mesmo,

Assim, em sua pesquisa, Faria (1988) buscou retratar a realidade escolar da criança da primeira série analisando os cadernos das crianças que cursaram a primeira série em escolas públicas do estado de Minas Gerais, em 1987, e realizou entrevistas com professores e alunos para compreender os escritos dos cadernos dos alunos. Faria (1988) buscou perceber as práticas em sala de aula através dos escritos nos cadernos dos alunos, isso nos ajuda a entender a importância dos conteúdos trabalhados em caderno de alunos, especialmente, em se tratando das questões étnico-raciais, cujo foco também é nosso. 
Faria (1988) em sua pesquisa mostrou que a escola pode contribuir para a construção de um projeto político pedagógico possibilitando as crianças construírem conhecimentos conforme suas particularidades, bem como, mostrou a relação das questões encontradas no caderno, com a escola e a sociedade.

E é nesse sentido que Faria (1988), apesar de anteceder a criação da lei 11.645/2008, vai nos ajudar a perceber as questões étnico-raciais nos cadernos que vamos analisar, já que, de acordo com Faria (1988, p. 3), "os cadernos ocupam esse papel e constituem as provas mais evidentes do trabalho que se desenvolve na escola". Assim, pensamos olhar se os conteúdos escritos no caderno dão conta de mostrar as questões étnico-raciais, conforme determina a lei citada.

Também anteriormente a 2008, encontramos a pesquisa desenvolvida por Lopes (2006), na qual aparece o tema em foco:

Nos cadernos escolares o tempo se assinala pela presença constante da data no início de cada dia escolar e o espaço a seguir é ocupado por atividades que parecem se manter com uma certa regularidade: cópias, ditados, contas, tabelas a preencher, problemas a resolver, redações, exercícios variados, registros de eventos particulares ao ambiente da sala e/ou da escola, registros de eventos locais e/ou nacionais... A distribuição das matérias presentes no caderno matemática, português, história, geografia, ciências - articula-se ao universo de conhecimentos socialmente instituídos, constituindo-se como expressão de representações sociais que manifestam, não ingenuamente, o caráter histórico e social da escola (Lopes, 2006, p. 49).

Apesar de não estar dentro do recorte estabelecido neste levantamento, Lopes nos auxilia na compreensão de que as práticas e cultura escolar podem estar (d)escritas nos cadernos dos alunos, podendo estes se tornarem um material empírico importante na busca de como vêm sendo construídos os discursos sobre as questões étnico-raciais nas escolas. Assim, Lopes vê "o caderno escolar como documento da narrativa escolar e suporte de um sistema linguístico e cultural. Nessa perspectiva, suas marcas identitárias estão estreitamente vinculadas a esse contexto e aos indivíduos que com ele interagem” (Lopes, 2006, p. 05). O caderno pode ser considerado um instrumento capaz de denunciar práticas colonialistas e /ou mostrar indícios de reconhecimento e respeito o outro por meio da valorização de sua cultura(s) e identidade, isso a partir da formação escolar deste.

Sobre o caderno escolar, também nos amparamos em Kirchner (2018) para entender que este pode ser considerado um importante material de pesquisa, pois o caderno compõe um elemento empírico carregado de narrativas, significados e discursos que nos (re)produzem, dependendo da perspectiva formativa utilizada no contexto escolar. Ribeiro (2018), a este respeito, aponta que a escola, em maioria, por meio de seu controle curricular colonialista, ainda é reprodutora dos conhecimentos eurocentrados e, neste controle, oportuniza a disseminando de pensamentos que minimizam e subalternizam aquele que não está "adequado" aos modelos coloniais/eurocêntricos.

A busca das produções já realizadas possibilitou perceber como estas pesquisas anteriores adentraram a temática, e como os processos teórico-metodológicos definidos contribuíram ou não nas investigações e análises de acordo com os objetivos propostos. O Quadro 2 abaixo, apresenta as pesquisas selecionadas a fazer parte deste artigo, as quais investigaram sobre os estudos das relações da educação étnico-racial de acordo com o que diz as leis já mencionadas, e documentos oficiais que norteiam a educação brasileira.

Quadro 2: Dissertações selecionadas para este recorte encontradas.

Tipo de pesquisa: Dissertação Ordem: No 01 Autor: MARTINS, Davi Silvestre Fernandes. Instituição: Programa de Pós-Graduação em Educação Universidade Estadual `Paulista Júlio de Mesquita Filho Ano: 2010 Título: A Lei 10.639/2003 o Cotidiano Escolar e as Relações Étnico-Raciais: um Estudo de Caso. Resumo: A escola se silencia sobre as questões étnicas, como indica a literatura especializada. Esse fato contribui para a marginalização de toda uma população pela cor da pele e descendência afro-brasileira. E no aspecto das relações étnico-raciais e da "Cultura e História Afro-brasileira", o direito que impulsionou o fim desse silêncio foi conquistado e reconhecido pelo Estado na forma de lei através da promulgação da Lei $\mathrm{N}^{\circ} 10.639$, em 2003 , os objetivos da presente pesquisa estão centrados na investigação das implicações da obrigatoriedade do estudo da temática de História e Cultura AfroBrasileiras\| no cotidiano escolar Resultado: Faltam estudos que analisem a repercussão da promulgação da Lei 10.639 na escola, e qual o significado que teve para educadores e educandos. 
Tipo de pesquisa: Dissertação Ordem: No 02 Autor: PONCIANO, Deize Denise Instituição: Pró-Reitora de Pesquisa e PósGraduação Universidade do Oeste Paulista Ano: 2011 Título: História e Cultura Afro-Brasileiras no Currículo de História do $6^{\circ}$ aos $9^{\circ}$ anos da Rede Oficial do Estado de São Paulo Resumo: A população negra no Brasil sob o ponto de vista histórico, sempre foi colocada à margem da sociedade. O processo de implementação da Lei 10.639/2003 e outros dispositivos legais tornam obrigatórios o ensino da História e Cultura afro-brasileira e africana, como conteúdo a serem inseridos em todas as disciplinas do currículo escolar, bem como discussões pertinentes à educação das relações étnico-raciais. O objetivo analisar como é desenvolvida e apresentada a História e Cultura afro-brasileira no Currículo do $6^{\circ}$ ao $9^{\mathrm{a}}$ anos de História do Estado de São Paulo, implementado a partir de 2008. Resultado: As análises revelaram que o Currículo não remete à atual situação do afro-brasileiro em nossa sociedade, sua importância na construção da História e Cultura brasileiras e, não propicia um debate consistente sobre a diversidade cultural, o preconceito e o racismo.

Tipo de pesquisa: Dissertação Ordem: No 03 Autor: SILVA, Regina Maria. Instituição: Programa de Estudos Pós-graduados em Educação: Currículo. Pontifícia Universidade Católica de São Paulo. Ano: 2014. Título: Educação das Relações Étnicos Raciais nos Cadernos Didáticos Formadores do Saber $(2011$ - 2012): Análise da Experiência da Rede Municipal de Santo André. Resumo: A pesquisa foi através da análise de conteúdo, o objetivo desta pesquisa foi investigar as abordagens das relações étnicos-raciais nos cadernos didáticos utilizados pela rede municipal de Santo André "Formadores do Saber (2011-2012), principais fontes de pesquisa foram a Lei $N^{\circ} 10.639 / 03$ e as Diretrizes Curriculares Nacionais para a Educação das Relações Étnico-Raciais e o Ensino de História e Cultura Afro-Brasileira e Africana (DCNERER). Resultado: Avaliou-se que o Ensino de História e arte foi trabalhado de modo integrado, mas somente no $4^{\circ}$ ano. Do $1^{\circ}$ ao $3^{\circ}$, os conteúdos enfatizam a valorização da identidade. Em Literatura, há um número significativo de obras africana do $2^{\circ}$ ao $5^{\circ}$, mas se notou ausência dos escritores afro-brasileiros.

Tipo de pesquisa: Dissertação Ordem: No 04 Autor: SILVA, Simeia de Oliveira Vaz Instituição: Pontifícia Universidade Católica do rio Grande do Sul - Pucrs programa de pós-graduação em história Minter Pucr/Fer Ano: 2015 Título: o Ensino da História e da Cultura Afro-Brasileira em Rondônia: A aplicação da Lei no 10.639/2003 Resumo: A investigação proposta está convencionada ao estudo do ensino da História e a aplicabilidade da Lei 10.639/2003, sobretudo em Rondônia. O objetivo foi analisar o livro didático de História, distribuído pelo Programa Nacional do Livro Didático (PNLD 2012). As análises partiram da Lei 10.639/2003, Parâmetros Curriculares Nacionais (PCNs) até as orientações da Secretaria de Educação de Rondônia (SEDUC), sendo o problema central levantado qual a visão da História da África e da Cultura Afro-brasileira está apresentada nos livros didáticos de História e se essa visão permiti a aplicabilidade da Lei. Resultado: Embora, apresentem uma África rica, diversa e livre de grandes estereótipos não é possível ao afrorondoniense uma identificação, a parte final é dedicada a sugerir uma proposta de ensino da História afro-Rondoniense.

Tipo de pesquisa: Dissertação Ordem: No 05 Autor: BORGES, Marley de Fátima Morais Instituição: universidade Estadual Paulista Júlio de Mesquita Filho Faculdade de Ciências Humanas e Sociais Ano: 2016 Título: O ensino de História, Cultura Africana e AfroBrasileira na Perspectiva da Lei $n^{\circ}$ 10.639/2003: Análise de Políticas Públicas na EE. Prof. Hélio Palermo, Cidade de Franca SP Resumo: O objetivo analisar como está sendo inserido o estudo de "História, Cultura Africana e Afro-Brasileira" e o seu nível de enraizamento à luz da Lei n ${ }^{\circ}$ 10.639/2003, na EE. Prof. Hélio Palermo, localizada na cidade de Franca São Paulo, fonte de informações o projeto político pedagógico da escola pesquisada, e o currículo das disciplinas de História, Filosofia, Sociologia, Geografia, Arte e Língua Portuguesa. Os referenciais teóricos utilizados têm como base estudos culturais. Resultado: Constatou-se a interação do trabalho dos professores com o currículo. Importante ainda é ressaltar que os registros nos diários e as entrevistas dadas por estes mostram que o trabalho cotidiano vai além dos conteúdos conceituais. Concluindo-se que o currículo em ação se faz presente, propiciando um ensinar e aprender amplos e positivos. Ficando, assim, evidente o enraizamento de práticas pedagógicas que asseguram as determinações da Lei $n^{\circ} 10.639 / 23$

Tipo de pesquisa: Dissertação Ordem: No 06 Autor: RODRIGUES, Renata Cordeiro Instituição: Universidade Estadual Paulista Júlio de Mesquita Filho Faculdade de Ciências Humanas e Sociais ano: 2016 título: a obrigatoriedade da temática história e cultura afro-brasileira e indígena na rede de ensino: um Estudo Sobre a Implementação da Lei no 11.645/08 no Conteúdo Programático das Escolas Públicas de Caucaia Resumo: Esta pesquisa trata de questões inerentes a aplicabilidade da referente Lei nos ambientes escolares, buscando a compreensão das conquistas relativas ao processo da formação de identidade cultural da sociedade nacional. Resultado Ao observar as grades curriculares do ensino fundamental dos anos finais, das escolas municipais de Caucaia, foi possível constatar que se faz alusão apenas à Lei 10.639, de 09 de janeiro de 2003, que também altera a Lei de Diretrizes e Bases da Educação Nacional, visando a inclusão da temática afro-brasileira, sem menção referente a questão indígena. Foi possível observar o desconhecimento dos educadores e da comunidade escolar acerca da Lei e da obrigatoriedade dos seus estudos e, portanto, o despreparo para difundir tais saberes ou lidar com questões relativas à discriminação e ao preconceito, presentes no cotidiano dos alunos.

Tipo de pesquisa: Dissertação Ordem: No 07 Autor: Ana Keuria Merces Araújo Instituição: Universidade Federal do Pará Instituto de Ciências da Educação Programa de Pós-Graduação em Educação Ano: 2016 Título: “Aqui na Escola Não Mudou em Nada Nosso Cotidiano, tudo é Como Antes": Um Estudo Sobre a Prática Pedagógica dos Professores Após a Implantação da Lei 10.639/2003 na escola do campo do Patauá na Amazônia Paraense. Resumo: O presente estudo tem como parâmetros de trabalhos dois campos de lutas com recentes e constantes mudanças curriculares na área da educação: a educação do campo e a educação das relações étnicos-raciais, a partir da implementação da lei 10.639/03. Resultado. Apontaram que havia desconhecimento das leis 10.639/3003 alterada para 11.645/2008 que obriga o ensino de história e cultura afro-brasileira e africana, bem como a falta de formação e conhecimento de professores a respeito das questões étnico-raciais.

Tipo de pesquisa: Dissertação Ordem: No 08 Autor: Rosália Maria Rodrigues de Campos Instituição: Universidade Estadual de Campinas Faculdade de Educação Ano: 2019 Título: Uma Análise do Negro no Material Didático: Avanços e Permanências Resumo: Pesquisadoras(es) da temática racial observaram ao longo dos anos uma representação social do povo negro em livros didáticos e essas comprovações científicas relatam o quanto essa apresentação tem deixado marcas profundas na criança negra, e mais ainda, diante de uma ideologia de dominação e poder com relação ao povo negro, esse segmento da sociedade considerada "elite" branca tem mantido seus privilégios. Resultado. Os resultados obtidos remetem à necessidade maior de formação do corpo docente sobre a temática racial, pois é a quem cabe as apresentações das propostas das autoras quanto às sugestões de leitura dos textos complementares, vídeos informativos e filmes para que aconteça uma apropriação reflexiva do conteúdo, além da limitação das horas destinadas às aulas de história.

Fonte: BDTD (organizado pelas autoras, 2021). 


\section{Resultados e Discussões}

Essas dissertações foram selecionadas porque, em alguns aspectos trouxeram em suas abordagens, as relações da educação étnico-racial no contexto educacional brasileiro, com foco no ensino de história e cultura afro-brasileira, ou nas Leis 10639//2003 e a Lei 11.645/2008.

A pesquisa de Martins (2010), intitulada “A Lei 10.639/2003 o Cotidiano Escolar e as Relações Étnico-Raciais: Um Estudo de Caso", discutiu conceitos de preconceito, discriminação, estigma, identidade, abordou sobre o movimento e estudos sobre negros, trouxe o contexto sobre o afro-brasileiro, e situações de estigmatização na escola. Também analisou as legislações que regulamenta a obrigatoriedade do ensino de história e cultura afro-brasileira. De modo geral, investigou o impacto que a promulgação da lei 10.639/2003 tinha no cotidiano escolar e nas relações de poder que se estabelecem na escola. A pesquisa de Martins (2010) pautou-se na abordagem qualitativa, análise documental, questionários, entrevistas, análise de documentos oficiais, e grupos focais, para análises e produções dos dados.

A pesquisa de Martins mostra que, enquanto os alunos pesquisados apontaram a lei 10.639 como uma direção para que discussões sobre as questões étnico-raciais na escola, os professores apontavam que não percebiam problemas relacionados as questões étnico-raciais na escola. Esta pesquisa possibilita entender que há necessidade de se pensar a escola num contexto formativo onde o respeito às diferenças pode ser ampliado e difundido entre a comunidade escolar, e que naquele período da pesquisa, os docentes careciam de formação para trabalhar tais questões no espaço escolar. Também, com base na pesquisa mencionada, percebemos uma negação das diferenças, onde o outro, o negro no caso, acabam sendo invisibilizados no contexto da escola. A falta de formação de docente sobre assunto pode levar a discursos estereotipados sobre a presença do negro/a nas ações didáticas docentes, assim, os conteúdos postos nos currículos escolares muitas vezes não são discutidos ou tensionados nas ações didáticas docentes.

Os conhecimentos sobre as questões étnico-raciais acabam chegando aos alunos de forma fragmentada. Assim, a pesquisa de Martins, apesar de estar pautada na Lei 10.639, ajuda a pensar os conteúdos das relações da educação étnico-raciais nas disciplinas de História, Geografia, Literatura e Educação Física nos anos iniciais, se foram/estão sendo abordados conteúdos sobre questões étnico-raciais a partir dos cadernos dos alunos, se foi/está sendo garantida a aplicabilidade a lei e se esta aparece nos conteúdos em todas as disciplinas do currículo. Enquanto os alunos apontaram a lei como norte para que que haja mais discussões, os professores afirmaram não perceberem problemas relacionados as questões étnico-raciais na escola, o que pode ser entendido por falta formação sobre assunto, ou justamente pela pouca visibilidade que estes conteúdos oferecem nos currículos escolares, que não houve percepção dos problemas relacionados a percepção dos alunos.

A pesquisa de Ponciano (2011) intitulada "História e Cultura Afro-Brasileiras no Currículo de História do $6^{\circ}$ aos $9^{\circ}$ anos da Rede Oficial do Estado de São Paulo" partiu de quatro etapas, discutiu sobre o ensino de história e cultura afro-brasileira na disciplina de história, apresentou as lutas dos movimentos negros para inserir a história da África nos curriculares escolares, trouxe conceitos de diversidade cultural, e preconceito racial, falou da criação da lei 10.639/2003, analisou o livro didático de história, e o currículo do estado de São Paulo. Pautou-se na abordagem qualitativa e análise documental, com o objetivo de analisar como eram desenvolvidos, e apresentados os conteúdos curriculares do sexto a nona série/ano, sobre a história e cultura afro-brasileira na disciplina de história nos cadernos de professores e alunos elaborados pelo estado São Paulo, de acordo com a obrigatoriedade da lei $N^{o} 11.645 / 2008$.

A pesquisa de Ponciano (2011) mostra que o currículo discutido até aquele ano não deu conta do contexto histórico dos negros brasileiros, analisando que tal currículo não construiu e nem apresentou de maneira consistente a importância da história e cultura afro-brasileira, exceto quando se tratava da escravidão. Na visão de Ponciano (2011) o currículo valoriza a versão eurocentrada, desprezando os conhecimentos outros no currículo do estado de São Paulo, contribuindo na continuidade do desconhecimento dos alunos sobre a história dos negros/as no Brasil do ponto de vista do colonizado/escravizado; 
Alguns livros trazem abordagens equivocada, depreciativas e negativas sobre a população negra, o que além de ocasionar constrangimento as crianças negras, contribui para a constituição de ideias de superioridade "racial" de um grupo sobre o outro, ou seja, alimenta postura racistas (Ponciano, 2011, p. 10).

Nos cadernos da sétima e oitava série/ano abordou conteúdos reduzido ao processo de escravidão. Cabe lembrar, que no caderno há sugestões que dão ao professor autonomia, o que nos remete a entender que poderiam haver uma maior exploração da temática, a forma como os conteúdos apresentados não mostra a importância, e valorização do negro na construção da nossa história, suas lutas e resistências, nem proporcionou conhecimentos que contribuísse na desconstrução do pensamento eurocentrado construído e reproduzido inclusive na escola.

A pesquisa de Silva (2014) Intitulada "Educação das Relações Étnicos Raciais nos Cadernos Didáticos Formadores do Saber (2011 - 2012): Análise da Experiência da Rede Municipal de Santo André" se deu a partir de três etapas, se limitou ao ensino da primeira a quinta série/ano do ensino fundamental anos inicias, discutiu conceitos do "Currículo, Racismo e Preconceito", acerca da elaboração dos "Cadernos Didáticos Formadores do Saber" em Santo André, São Paulo tendo como foco o ensino de arte, história e literatura com base na lei $\mathrm{N}^{\circ}$ 11.645/08. Pautou-se na análise do discurso com objetivo de analisar a possibilidade de realização da inserção de uma política da educação das relações étnico-raciais nos "Cadernos Formadores do Saber".

Rosemberg et al. (2003) afirma que pesquisas realizadas mostraram que o livro didático era um dos principais responsáveis pelas desigualdades no currículo escolar, enquanto Silva, (2014) afirma que 98\% das escolas públicas brasileiras usam o livro didático como norteador curricular. Cabe lembrar, os cadernos formadores do saber substituem o uso do livro didático em Santo André. Contudo, este não superou as lacunas deixadas pelo livro didático, e não atendeu como previsto a aplicabilidade da Lei.

A pesquisa de Silva (2014) mostra que o livro didático tem sido um dos principais responsáveis pelas desigualdades no currículo escolar, afirmando que cerca de $98 \%$ (noventa e oito por cento) das escolas públicas brasileiras usam o livro didático como norteador curricular. Nos resultados por Silva (2014), não aparecem conteúdos que versam sobre as questões étnico-raciais nos conteúdos trazidos nos livros didáticos. De acordo com Silva (2014) os Parâmetros Curriculares Nacionais/PCNs priorizam a história local nestas série/ano, embora a lei 11.645/2008 determina que estes conteúdos sejam trabalhados em o todo ensino básico.

Os conceitos que apareceram com regularidade são: cultura (oito vezes), africana (cinco vezes), diversidade (quatro vezes), colonização (quatro vezes) e história (duas vezes). Em suas reflexões Silva (2014) deixa entender que pouco se pensa na na obrigatoriedade da lei em todas as disciplinas curriculares do ensino básico, isso nos leva a perceber a dificuldade na efetivação da Lei 11.645/2008.

A pesquisa de Silva (2015) intitulada "o Ensino da História e da Cultura Afro-Brasileira em Rondônia: A aplicação da Lei no 10.639/2003" discutiu a História da África e da Cultura Afro-Brasileira, a viabilidade da Lei 10.639/2003, traçou o perfil sobre a identidade afro-Rondoniense e discutiu sobre o movimento negro do estado, analisou os três livros de história das três séries finais do ensino médio do Programa Nacional do Livro e do Material Didático/PNLD 2012 para compreender se a História da África e da Cultura Afro-brasileira, mostrando que o livro investigado foi capaz de permitir aos afro-Rondoniense o reconhecimento de sua identidade.

Silva (2015) buscou entender como originou a presença e a formação da identidade afro-rondoniense, que deram seus primeiros sinais a partir do século XVIII e continuou com a chegada dos haitianos em Rondônia desde 2011, embora a migração negra iniciou no período em que se formava o estado onde os sujeitos vinham trabalhar na construção da Estrada de Ferro Madeira Mamoré, em 1912, também com as migrações ocasionadas pelos ciclos econômicos. Apresentou sobre o movimento negro no estado, fatores que contribuíram para formação da atual identidade afro-rondoniense. Embora a história do estado tenha 
suas especificidades, continuam fazendo parte da história geral do Brasil que assim como os demais estados brasileiros contaram com a presença de descendentes e negros escravizados que foram traficados da África.

Silva (2015) buscou perceber como o livro didático de história apresenta os conteúdos curriculares a serem ministrados sobre a história da África e da cultura afro-brasileira considerando as especificidades do ensino da história afro-rondoniense, depois propôs sugestões para o ensino da História afro-rondoniense para dessa forma contribuir com um ensino de história mais concreta em se tratando da realidade da história local, com intuindo de alcançar os propósitos da DCNERER e da Lei 11.645/08. A pesquisa ainda mostra que a coleção História Global Brasil e Geral é um exemplo de mudança e adaptação a Lei 10.639/2003, e que, por mais que haja orientações e avanços a respeito da temática, não há aprofundamento sobre as questões da história e cultura afro-brasileira.

A pesquisa de Borges (2016) discutiu a formulação e implementação do currículo como sendo um jogo de força e pode, descreveu as características físicas onde a pesquisa foi realizada, o objetivo foi analisar como está sendo inserido o estudo de História, Cultura Africana e Afro-Brasileira e o seu nível de enraizamento à luz da Lei no 10.639/2003, na EE. Prof. Hélio Palermo Franca/São Paulo. Pautou-se na abordagem qualitativa, usou entrevistas semiestruturadas com gestora e professores, analisou o projeto político pedagógico, além do currículo das disciplinas de História, Filosofia, Sociologia, Geografia, Arte e Língua Portuguesa desta escola. O referencial teórico teve como base os estudos culturais.

Borges (2016) traz em sua pesquisa uma discussão muito importante a respeito do currículo, por esse ser um dos principais instrumentos para inserção dos conteúdos, e por estar em constante reformulação, e por este determinante para o que chega e será ensinado em sala aula, além de ser indispensável para a formação do sujeito que será inserido na sociedade. Nesse sentido, cabe lembrar que este pode estar sendo um dos maiores obstáculos para efetivação da lei em se tratando do que é inserido dentro da sala de aula, considerando os aspectos que envolve a construção do currículo escolar no Brasil, assim concordo com Borges (2016, p. 43):

O ensino universalista adotado no Brasil não leva em consideração a diversidade da constituição do povo brasileiro. Nesse ínterim, se faz necessária uma nova proposta educacional com um olhar que passa pela lógica da diversidade, na qual se constitui a nação brasileira. Observando que todo processo de ensino nacional, até as últimas décadas do século XX, foi pautado na hegemonia ocidental de dominação masculina, branca e heterossexual, o qual não levava em consideração a cultura e os valores indígenas e africanos que, juntamente com a cultura europeia, contribuíram para a formação identitária brasileira.

Assim, as fontes pesquisadas apontaram que há dificuldades na efetivação da lei, e sua implantação na escola, embora sugere que curso de formação continuada seja importante nesse processo de efetivação da lei (Borges, 2016). Nesse sentido, o Projeto Político pedagógico/PPP da escola pesquisada, após reformulação incluiu questões africanas, com projetos que dão prêmios com viagens ao ganhadores ao museu Afro-brasileiro em São Paulo, incluem ações interdisciplinares direcionadas ao combate à discriminação racial e à valorização da cultura africana e afro-brasileiro, onde o corpo docente da escola foi importante na efetivação destas propostas que vem contribuem nas relações da educação étnico-raciais de forma proveitosa nesta escola.

Foi analisado o diário de classe como uma fonte rica, e importante para obtenção, e confirmação de práticas educativas, as quais confirmou-se comprometidas com as determinações da Lei $\mathrm{n}^{\circ} 10.639 / 03$, com registros nas disciplinas de História, Língua Portuguesa, Arte e Sociologia de conteúdos étnico-raciais, que inclusive discutiu o mito da democracia racial que ainda é presente no país, apresentou filmes a respeito à temática em questão, assim, contribuiu na efetivação da lei valorizou a cultura africana e afro-brasileira escola, no processo de formação dos alunos que inclusive passaram a participar de mais eventos na escola.

A pesquisa de Rodrigues (2016) Intitulada "Universidade Estadual do Ceará Centro de Estudos Sociais Aplicados Mestrado Profissional em Planejamento e Políticas Públicas - MPPP” discutiu sobre a presença dos negros e indígenas na 
sociedade brasileira abordando a lei 11.645/2008 e teve o objetivo de investigar o desenvolvimento da implementação da Lei ${ }^{\circ}$ 11.645, em duas Escolas de Ensino Infantil e Ensino Fundamental anos iniciais do município de Caucaia/Ceará.

Segundo Rodrigues (2016) apesar de a Secretaria Municipal de Educação (SEMED) de Caucaia/Ceará realizar a compra de vários livros para o acervo das bibliotecas locais e realizar ações voltadas para as relações da educação étnico-raciais, mesmo sendo ações positivas, não foi suficiente para atender a aplicabilidade da referida lei. Para Rodrigues (2016) houve falta de discussões e conhecimentos sobre a temática tanto pelos alunos que assumiram desconhecer a lei, seu conteúdo e sua obrigatoriedade, quanto pelos professores, reforçando o desconhecimento da lei e a falta de formação continuada dos educadores têm sido obstáculos para discutir a temática dentro de sala de aula, pois no currículo oficial não havia conteúdos a respeito das questões étnico-raciais.

Os dados mostrados por Rodrigues (2016) trouxeram revelações que, confirma está havendo discussões a respeito da temática, a priori fora da sala de aula, ou seja, os conteúdos do currículo oficial ainda não compõem de discussões a respeito das questões étnico-raciais dentro de sala de aula.

Embora a priori os alunos não tivessem conhecimento da determinação da lei, estes perceberam a importância que estas discussões representariam em sua formação, pois, a maioria dos participantes afirmaram terem vivenciado preconceito racial no próprio espaço escolar. Assim, a falta de discussões, e conhecimentos sobre a temática é foi evidenciando tanto pelos alunos, que assumem desconhecerem a lei, seu conteúdo, e sua obrigatoriedade, quanto por professores, o que vem reforçando resultados das dissertações selecionadas realizadas em anos anteriores a essa, que o desconhecimento da lei, e a falta de formação continuada dos educadores têm sido obstáculos para efetivação desta lei, e que a educação no Brasil continua a passos lentos, especialmente se tratando de discussões sobre as questões étnico-raciais.

Araújo (2016) buscou investigar como objetivo principal as práticas pedagógicas dos professores de uma escola do campo no interior do Pará em Tapauá, , especialmente se pensarmos que já se passavam nesta época 13 anos da implantação da primeira lei e 08 anos de sua alteração sob o título "aqui na minha escola não mudou em nada nosso cotidiano, tudo é como antes" em se tratando do título já subtendemos a pesquisa, e pensado a situação que se estende as condições de escolas do campo, é possível que as dificuldades da implementações de leis sejam mais precárias quando se trata de efetiva-las embora a escola urbana nesse sentido não venha trazendo grandes avanços.

A pesquisa de Araújo (2016) foi realizada a partir de três etapas buscou discutir a educação dos campos e as questões étnico-racial, seguiu os caminhos investigativos inclusive que incluía etapa no cotidiano da escola, por fim se deu as análises da pesquisa. Ao realizar suas visitas a escola foco da pesquisa, a autora presenciou de forma continua, e naturalizada o racismo explícito em falas pejorativas e comportamentos de tido como brincadeiras, de colegas para colegas, bem como de professores e funcionários para com os alunos, sendo usado segundo Araújo (2016) termo como (negrinho, pretinhos, filho da noite, carvão entre outros). Assim, seus resultados mostram que o seu título faz todo o sentido no que se refere ao distanciamento da lei e a realidade daquela escola que, professores não conhecia a lei nem sua obrigatoriedade, além disso, admitem que não possuí domínio sobre as questões étnico-racial, e que não há nenhum tipo de formação que os ajude a acompanhar as mudanças curriculares e leis.

Uma outra pesquisa que nos traz reflexões importantes, por ser ainda mais recente, e ao mesmo tempo já tão distante do tempo de implementação das leis 10.639/2003 aletrada para 11.645/2008. A Pesquisa de Campos (2019) que teve como objetivo analisar a presença do negro no material didático do Ensino Fundamental um da cidade de Itu, lembrando que o estado de são Paulo produza seu próprio caderno do professor e do aluno, a partir de orientações e leis que regem o currículo escolar no Brasil.

A pesquisa de Campos (2019) foi realizada em três etapas, buscou focar para os avanços e permanências no ensino das questões étnico-raciais através dos livros didáticos. Para isso a autora discutiu como se dá a representação social do negro, a 
questão do branqueamento, identidade negra e o racismo no Brasil, mesmo "o povo negro no Brasil, apesar de ser maioria, recebe uma definição sociológica de minoria, tendo em vista que sociologicamente o que tem valor e sentido é o modo de pensar de um grupo sobre o outro" (Campos, 2019, p. 22) mesmo que esta pesquisa tenha encontrado avanços ainda é pouco significante considerado que somos a maioria da população, sabendo que esta pesquisa é amostra de uma cidade brasileira.

Assim, Campos (2019) afirma que foram encontrados avanços nos conteúdos encontrados sobre afrodescendentes, história e cultura africana, trazendo questões relevantes, e de forma respeitosa que valorizaram a diversidade cultural africana, assim como, também houve uma postura positiva em relação a preocupação em descontruir estereótipos que vem marcando a história dos negros e da África de modo geral. Mas, ainda assim, foi encontrado insistência em tratar a invasão europeia como ocupação, o escravismo liderado pelos europeus sem diferenciação de outras situações de escravismo, tratar uma criança negra como uma mascote de turma, tratar como se fosse inexistente as lutas dos africanos nas relações comerciais, e não referenciar as marcas e imposições que havia nesta relação.

As pesquisas aqui elencadas mostram que, apesar de haver a obrigatoriedade de abordar conteúdos relacionados às questões étnico-raciais, só poderá haver um ensino efetivo que dê conta de subverter os estereótipos e racismos, em suas variadas formas, se houver discursos escolares que favoreçam tais reflexões.

\section{Considerações Finais}

Os autores dos trabalhos apresentados reconhecem que ainda há muitas lacunas deixadas quando se trata da aplicabilidade das Lei 10.639/2003 e 11.645/2008, seja em São Paulo, Rondônia, Ceará ou outros estados brasileiros. Nesse sentido, entendemos que, para que haja de fato a efetivação das leis referidas, é preciso empenho e um currículo que permita a efetivação de práticas escolares que caminham neste sentido. As pesquisas mostram que a escola é um dos locais de cultura, onde os discursos de identidade aparecem e se produzem. Os conteúdos escolares, articulados aos discursos eurocêntricos reproduzem estereótipos e muitas vezes invisibilizam conhecimentos advindos de culturas "menores". A prática docente deve estar voltada para o contexto da diversidade e das diferenças, assim, por mais que os materiais didáticos produzam discursos polarizadores, binários, racistas e preconceituosos, é possível questionar e subverter tais processos.

É preciso ressaltar a maneira como os conteúdos foram conduzidos sem explorar e valorizar a história e cultura africana e afro-brasileira, sua diversidade étnica, religiosa, bem como a alegria e o colorido e cultura desses povos, como determina a lei 11.645/2008, e documentos oficiais que norteiam a educação brasileira que haja exploração em torno de todos os aspectos referente a relação da educação étnico-racial, enfatizando a ideia que remete a tristeza, pobreza e a fantasia. Percebeu-se, no entanto, o prestigio da figura do branco, quando se referia a figura do negro era enfatizado de forma negativa.

Todas as pesquisas foram importante para perceber como vêm acontecendo ou não a efetivação das leis $\mathrm{N}^{\circ} 10.639 / 2003$ e 11.645/2008, embora seus resultados não surpreenderam quanto a ausência destas discussões, mas, contribuíram a pensar sobre como tem sido trabalhado sobre as questões étnico-raciais, lembrando que o livro didático é dos principais instrumentos para orientação desses conteúdo a serem trabalhados na maioria das escolas públicas do país, não é o único meio ou instrumentos para exploração da lei.

As pesquisas que investigaram os cadernos de alunos e professores como objeto empírico, e que foram elaborados após a criação das leis já mencionadas, também me ajudaram a perceber que há novos caminhos a serem explorados para obtenção de novos conhecimentos e respostas. Embora, estes cadernos tenham deixado a desejar ainda mais, por se tratar de instrumento novo elaborado para o ensino, os quais deveriam estar atentos quanto a aplicabilidade das leis, e documentos oficias, atuais e vigentes para a educação no país.

Estas pesquisas mostraram que ainda há muita luta para que haja de fato a efetivação das leis 10.639/2003 e 11.645/2008, bem como trabalhar sobre as questões étnico-racial, a desconstrução do pensamento eurocentrado, o racismo, a discriminação e 
o preconceito em nossa sociedade, que deixa a desejar na formação dos educandos, bem como na ideia que constrói sobre sua identidade étnico-racial, por desconhecerem a importância do negro e afrodescendentes na construção da história do país, o que alimenta a desigualdade entre os sujeitos.

Assim, pensando nas lacunas deixadas por estas pesquisas que se limitarem nas disciplinas sugeridas pela lei, especialmente na disciplina de história, pude perceber a importância de realizar esta nova pesquisa, as metodologias ajudaram a perceber que a aplicabilidade das leis sobre o ensino das relações educação da étnico-racial, pode ser buscado como pretendida com cadernos usados pelos alunos de primeira a quinta série/ano de todas as disciplinas do contexto educacional de Humaitá/Amazonas como principal artefato empírico de pesquisa, como possibilidade de trazer novos conhecimentos e reflexões para pensar as questões étnico-racial considerando que estamos à dezoito da implementação lei 10.639/03, e há 13 anos da lei 11.645/2008 alterou e contemplou a história e cultura indígena.

Por fim, percebemos que há urgência na efetivação das leis 10.639/2003 e 11.645/2008 em todo currículo escolar, não somente na disciplina de história, arte e literatura, que os professores precisam usar sua autonomia como mediador do conhecimento, e se apoderar de conhecimentos sobre a temática, usar das brechas deixadas nas sugestões tanto do caderno do professor, como do livro didático, que o currículo escolar ainda não se aprofunda, nem tem procurado descontruir ideias eurocentradas. Cabe lembrar que a escola e o currículo escolar são os maiores responsáveis por (re)produzir conhecimentos, culturas e identidades.

Desta maneira, devido a importância desta temática, bem como a necessidade de desconstrução de ideias de disseminadas pelos colonizadores que legitima os conhecimentos eurocentrado, que reproduzido nos mais diversos espaços especialmente na escola, que pensamos ser possíveis novas investigações sobre como está sendo trabalhados os conteúdos étnicoraciais no ensino médio, para que possamos buscar perceber como está o processo de construção do conhecimento na etapa final do ensino básico com relação ao que refere-se a obrigatoriedade da Lei № 11.645/2008 e sua aplicabilidade.

\section{Referências}

Araújo, A. K. M. (2016). Aqui na escola não mudou em nada nosso cotidiano, tudo é como antes: um estudo sobre a prática pedagógica dos professores após a implantação da lei 10.639/2003 na escola do campo do Patuá na Amazônia paraense. (Dissertação de Mestrado em Educação). Universidade Federal do Pará.

Bhabha, H. K. (2013). O Local da Cultura.. (2a ed.), Ed. UFMG.

Bauman, Z. (2005). Identidade. Zahar.

Borges, M. F. M. (2016). O Ensino de história e cultura africana e afro-brasileira, na perspectiva da Lei № 10.639/2003: analise de políticas públicas na EE. Prof. Hélio Palermo, cidade de Franca/São Paulo. (Dissertação de Mestrado em Planejamento e análise de políticas públicas). Universidade Estadual Paulista Júlio de Mesquita Filho.

Brasil. (1996). Lei nº 9.394, de 20 de dezembro de 1996. http://www.planalto.gov.br/ccivil_03/Leis/L9394.htm

Brasil. (2003). Lei no 10.639 de 09 de janeiro 2003. L10639 (planalto.gov.br)

Brasil. (2008). Lei n 11.645 de 10 de março de 2008. L11645 (planalto.gov.br)

Campos, R. M. R. (2019). Uma Análise do Negro no Material Didático: avanços e permanências. (Dissertação de Mestrado em Educação). Universidade Estadual de Campinas.

Chauma, S. I. M. \& Alves, M. I. A. (2020). Produções científicas acerca dos ritos de iniciação e suas influências no processo educacional em Moçambique. Revista Humanidades e Inovação, v.7, n.7.7.

Costa, M. V. (2007). Uma agenda para jovens pesquisadores In: Costa, M. V. Caminhos investigativos II: outros modelos de fazer pesquisa em educação. Lamparina.

Faria, V. L. B. (1988). No caderno da criança o retrato da escola. (Dissertação de Mestrado em Educação). Universidade Federal de Minas Gerais.

Fernandes, J. (2017). Da trajetória escolar ao sucesso profissional: narrativas de professoras e professores negros. Appris.

Hall, S. \& Woodward, K. (2013). Identidade e Diferença: a perspectiva dos estudos culturais. Silva, T. T. (Org). (13a ed.), Vozes.

Kirchner, C. A. S. M. (2018). A análise do caderno escolar como recurso didático nas aulas de história da educação. Pedagogia em Foco, 13(10). 
Research, Society and Development, v. 10, n. 11, e337101119649, 2021

(CC BY 4.0) | ISSN 2525-3409 | DOI: http://dx.doi.org/10.33448/rsd-v10i11.19649

Lopes, I. C. R. (2006). Memória e discurso em marcas de correção: um estudo de cadernos escolares. (Dissertação de Mestrado em Memória Social). Universidade Federal do Estado do Rio de Janeiro.

Ludke, M. \& André, M. E. D. A. (2013). Pesquisa em educação: abordagens qualitativas. (2a ed.), E.P.U.

Martins, D. S. F. (2010). A lei 10.639, o cotidiano escolar e as relações étnico-raciais: um estudo de caso. (Dissertação de Mestrado em Educação). Universidade Estadual Paulista Júlio de Mesquita Filho.

Meyer, D. E. \& Paraíso, M. A. (2012). Metodologias de pesquisas pós-críticas em educação. Mazza edições.

Morosini, M. C. \& Fernandes, C. M. B. (2014). Estado do conhecimento: conceitos, finalidades e interlocuções. Educação Por Escrito, 5(2), 154-164.

Nunes, R. B. (2017). Tentando entender a diferença: por que afrodescendente e não negro, pardo, mulato, preto? Revista África e Africanidades. Ano X, n. 24.

Ponciano, D. D. (2011). História e cultura Afro-Brasileiras no currículo de história do $6^{\circ}$ aos 9 anos da rede oficial do estado de São Paulo. (Dissertação de Mestrado em Educação). Universidade do Oeste Paulista.

Queiroz, D. M. (2004). Universidade e desigualdade: brancos e negros no ensino superior. Liber.

Quijano, A. (2005). Colonialidade do poder, eurocentrismo e América Latina. In: LANDER, Edgardo. Colonialidade do saber, eurocentrismo e ciências sociais: perspectivas latino americanas. Buenos Aires: Clacso.

Ribeiro, D. (2018). O Conhecimento Moderno-Ocidental à luz do pensamento decolonial Latino-Americano: aprender, desaprender e reaprender a partir dos movimentos Sociais. Currículo sem Fronteiras, 18(3).

Rodrigues, R. C. (2016). A obrigatoriedade da temática história e cultura afro-brasileira e indígena na rede de ensino: um estudo sobre a implementação da lei $n^{\circ} 11.645 / 08$ no conteúdo programático das escolas públicas de Caucaia. (Mestrado Profissional em Planejamento e Políticas Públicas). Universidade Estadual do Ceará.

Romanowski, J. P. \& Ens, R. T. (2006). As pesquisas denominadas do tipo “estado da arte” em educação. Diálogo Educacional, 6(19).

Rosemberg, F., Bazilli, C. C. C. \& Silva, P. V. B. (2003). Racismo em livros didáticos brasileiros e seu combate: uma revisão da literatura. Educação e Pesquisa, 29(1), p. 125-146.

Silva, R. M. (2014). Educação das relações étnico-raciais nos cadernos didáticos "Formadores do Saber” (2011-2012): análise da experiência da rede municipal de Santo André. (Dissertação de Mestrado em Educação). Pontifícia Universidade Católica de São Paulo.

Silva, T. T. (1999). Documentos de identidade: uma introdução às teorias do currículo. Autêntica.

Silva, S. O. V. (2015). O Ensino da história e da cultura Afro-Brasileira em Rondônia: a aplicação da Lei nº 10.639/2003. (Dissertação de Mestrado em História). Universidade Católica do Rio Grande do Sul. 